\title{
Las mujeres periodistas en primera línea: reporteras en la cobertura de conflictos
}

Montserrat Jurado Martín | mjurado@umh.es

Universidad Miguel Hernández

\section{Libro:}

Del Paso, A. (Coords.) (2018). Reporteras españolas, testigos de guerra. De las pioneras a las actuales. Barcelona: Penguin Random House Grupo Colección: Debate. ISBN: 978-84-9992-830-2, 334

págs.

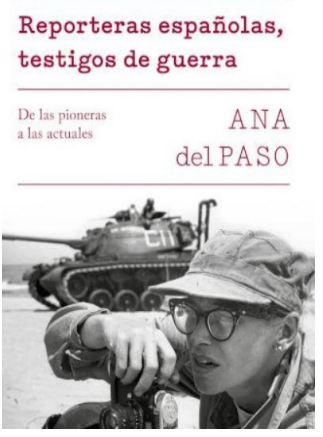

Cómo citar este texto:

Montserrat Jurado Martín (2020): Las mujeres periodistas en primera línea: reporteras en la cobertura de conflictos, Miguel Hernández Communication Journal, Vol. 11 (2), pp. 345 a 350. Universidad Miguel Hernández, UMH (Elche-Alicante). DOI: http://dx.doi.org/10.21134/mhcj.v11i0.348

How to cite this text:

Montserrat Jurado Martín (2020): Women journalists on the front line: reporters in conflict coverage, Miguel Hernández Communication Journal, Vol. 11 (2), pp. 345 a 350. Universidad Miguel Hernández, UMH (ElcheAlicante). DOI: http://dx.doi.org/10.21134/mhcj.v11i0.348 
Es complejo ser del todo objetivo durante la lectura de este libro. Y eso es probablemente una de las grandes joyas que se encuentran en sus páginas. Prácticamente, desde el inicio y hasta el final, el pensamiento del investigador que lo tiene entre sus manos, se evade y piensa sobre 'qué haría yo en esa situación'. La autora, Ana del Paso, logra con un texto emanado de un estudio exhaustivo sobre las mujeres periodistas en situaciones de conflicto y durante su desarrollo profesional, que el lector empatice con las entrevistadas desde el enfoque literario, como protagonistas de una historia novelada. Esta consecuencia, que deriva del método de investigación y, sin quererlo, concluye en una publicación que se aproxima más a la de una novela, en el que seguimos la historia de 34 reporteras de guerra, desde que se les plantea, o se plantean, la posibilidad de cubrir una guerra, hasta los momentos de reflexión posteriores a su regreso o cuando se ha dado por finalizada la cobertura.

No cabe duda de que el resultado de este libro tiene mucho que ver con la implicación personal de la autora en él. El volumen consta de poco más de 300 páginas con un estilo ágil que no abandona en ningún momento el proceso de una investigación de calidad. Consta de 11 capítulos a los que antecede un prólogo y una introducción y queda cerrado por un epílogo, unas notas generales, la bibliografía y agradecimientos finales. Introduce el libro afirmando que se trata de una "deuda personal" con todos los compañeros con los que ha compartido algún conflicto armado, "unas veces me sacaron de apuros, otras, me ayudaron a alcanzar mis objetivos, y algunas, aunque me lo pusieron difícil, reforzaron mi empeño de mostrar, a toda costa, la cara oculta de la guerra”.

El libro supone un compendio de declaraciones extraídas a partir de entrevistas en profundidad a 34 mujeres periodistas que han cubierto conflictos armados desde 1980 y hasta la actualidad. Explica que se trata de entrevistas que, a su vez, han servido de clases magistrales de reporterismo y que "en ellas queda patente la pasión por el periodismo, una profesión desprestigiada que debe soportar el intrusismo profesional, el mal uso de las redes sociales, la mediocridad y la propaganda".

Los capítulos de Introducción y el de Pioneras tienen un enorme valor en la historia del periodismo de España desde el enfoque de la mujer periodista, poniendo nombre y apellidos a personas, a periodistas mujeres, que no suelen ser nombradas en los anales del periodismo, que, como toda la historia, parecen no haber existido. Descubrimos un capítulo que recuerda que no sólo estuvieron allí, sino que además de cubrir el conflicto bélico, debían superar el 'conflicto' de género frente a sus compañeros hombres.

Las entrevistadas son: Almudena Ariza, Ángeles Espinosa, Beatriz Mesa, Berna González Harbour, Carmen Postigo, Carmen Sarmiento, Corina Miranda, Ana Alba, Cristina Sánchez, Esther Vázquez, Ethel Bonet, Georgina Higueras, Gloria del Campo, Gemma Parellada, Laura Jiménez Varo, Leticia Álvarez, Lola Bañón, María Dolores Masana, Maruja Torres, Maysun, Mayte Carrasco, Mercedes Gallego, Mónica Bernabé, Mónica G. Prieto, Naiara Galarraga, Natalia Sancha, Olga Rodríguez, Pilar Requena, Trinidad Deiros, Yolanda Sobero, Rosa Meneses, Rosa María Calaf, Teresa Aranguren y Yolanda Álvarez. Además, se deben sumar las opiniones de la propia autora, que, como profesional en conflictos, también se añade de forma tímida, pero sobradamente justificada, al listado.

El libro organiza las declaraciones por contenido, es decir, ni es cronológico, ni por perfiles de entrevistadas, ni por fecha de antigüedad, nacimiento, o años en activo de éstas. Sigue por lo tanto un criterio periodístico interpretativo, ofreciendo un orden de importancia de los contenidos dosificado por el interés del lector. Tanto es así, que, para no perder la intensidad, destacan dos 
capítulos: el octavo y el undécimo. Matar al mensajero llama la atención por la combinación que ofrece el ejercicio de este tipo de periodismo con el verbo tan noticioso como es 'matar', y el último, de plena vigencia, sobre la objetividad, capítulo con el que finaliza. Pero vayamos por partes:

En el capítulo 1, Pioneras, se lleva a cabo una revisión de las grandes precursoras del periodismo de conflicto. Como se ha mencionado antes, este capítulo debería formar parte de los libros de historia del periodismo español, por la riqueza de contenido y por lo poco tratado que está en todos los ámbitos. En el capítulo 2, En pie de guerra, Del Paso explica que:

"Las protagonistas de este libro han logrado hacerse un hueco en una especialidad aún dominada, al menos en número, por los hombres. Todas han defendido una postura frente a la manipulación, la intoxicación y la propaganda procedente de los bandos beligerantes. Algunas han sido perseguidas, expulsadas del país en el que desempeñaban su trabajo, amenazadas, espiadas, retenidas, vetadas o les han disparado".

De estos inicios, la autora llama Década Prodigiosa a los años sesenta del periodismo por los acontecimientos históricos que les tocaron vivir: "la caída del muro de Berlín, la desaparición de la Unión Soviética y de países como Yugoslavia, la invasión de Kuwait, la caída de dictadores en Sudamérica o los genocidios en África y en Europa". Gran parte de las entrevistadas forman parte de las profesionales que cubrieron estos conflictos, lo que da un valor añadido a las declaraciones que aquí se recogen.

En el capítulo 3, Cuando hay que volver a casa, la autora explica el sentir común de que a "todas las periodistas de este libro les gustaría poder dedicar más tiempo a las coberturas en los destinos a los que las destacan". Estima que para comprender la magnitud de los acontecimientos en una zona de conflicto es imprescindible informar sobre ellos en sus tres etapas clásicas: situación prebélica, el conflicto armado y la posguerra. En esta parte resulta de interés todo lo relativo a lo caro que le resulta a un medio enviar a un equipo a cubrir un conflicto. Del Paso analiza el proceso de aprendizaje que llevaron a cabo los medios de comunicación en relación al cálculo del presupuesto para el envío de un equipo para cubrir una guerra, incluyendo la formación que estos requerían antes de su partida. Explica que muchos de los protocolos que hoy en día se siguen se aprendieron por la experiencia asimilada en la década de los 90 y, sobre todo, con la primera guerra del Golfo.

En el capítulo 4, La verdad de la 'verdad' en la guerra, la autora afirma que "es complicado desentrañar los hechos, ya que, normalmente, quién puede no tiene intención de hacerlo y ahí radica el trabajo de la periodista, en buscar la verdad, verificar los datos, sintetizarlos, contextualizarlos, interpretarlos y ponerlos a disposición del público". Resulta reveladora en relación a los criterios que determinan qué contenido difundir y qué no: "la autocensura es mucho más habitual de lo deseable y, a veces, no se hacen públicas las verdades porque podían afectar negativamente a los intereses económicos y empresariales el propio medio". Este bloque habla fundamentalmente de la necesidad de encontrar la verdad, de sus dificultades y de cómo a veces incluso teniendo esta información no puede usarse.

En el capítulo 5, Esquivar la censura en tres sencillos pasos, se habla de las técnicas que han utilizado las periodistas para poder evadir la censura, fundamentalmente, la que proviene de las fuentes a las que hay que preguntar y, sobre todo, de las gubernamentales. Es un capítulo de gran riqueza anecdótica que debe entenderse en el contexto en el que se ha dado cada uno de los ejemplos que se describen. 
En el capítulo 6, Colegas en la guerra, guerra entre colegas, habla de la competencia entre compañeros, de cómo, en ocasiones, en sana y, en otras, no lo es. En general destaca el compañerismo entre profesionales de diferentes medios que realmente son competencia, pero que, en este tipo de contextos, deben colaborar para obtener información contrastada. También se dedican fragmentos a mencionar la relación entre hombres y mujeres, y de cómo a veces no son las mejores. Cabe destacar una de las declaraciones que hace Rosa María Calaf cuando crítica como a algunos periodistas independientes se les piden "el más difícil todavía, aunque no necesariamente vaya acompañado de calidad informativa, sino impacto mediático pues de otro modo los medios no les compran un reportaje". Esta competitividad supone en ocasiones un riesgo para su seguridad y su vida que económicamente no está compensado.

En el capítulo 7, Relaciones a distancia: la redacción, se habla de las relaciones personales y profesionales entre la periodista que cubre el conflicto y la empresa, centrando sobre todo el objetivo en el trabajo de redacción, en cómo se cortan los textos y de cómo a veces pierden su sentido. Tal y como explica:

"La mala edición es una de las bestias negras de los periodistas. Algunos editores destrozan las crónicas cuando las diseccionan y las corrigen en su mesa. Es esencial que los correctores sean pulcros y conozcan el asunto que se aborda en la pieza cuando llega la hora de revisarla, de lo contrario el resultado será chapucero y la crónica irreconocible".

En el capítulo 8, Matar al mensajero, habla de las situaciones de acoso y ciber acoso en la que se encuentra muchos periodistas cuando se les acusa de no ser imparciales. Se trata de un capítulo que aborda de manera valiente una situación poco conocida y muy dura. En el capítulo 9, De cómo ponerse en chaleco antibalas, las entrevistadas describen la escasa preparación previa que tuvieron desde el punto de vista físico, psicológico y emocional, del contexto y las fuentes, etc. Algunas recuerdan que toda esa falta de experiencia, hoy en día, se ha cubierto con la oferta de cursos formativos especializados, que tiene un alto coste para las empresas, pero que resultan efectivos y básicos. Se trata de un capítulo que, además, puede resultar curioso para los lectores ajeno a la profesión.

En el capítulo 10, Imágenes que cortan la respiración, las entrevistadas contestan acerca de la difusión o no de ciertas imágenes, y de si su contenido terminará inmunizando al público. Hay declaraciones en ambos sentidos, y, aunque no resulta concluyente, sí es interesante desde el punto de vista de que siempre habrá opiniones en pro y en contra. En el capítulo 11, Objetividad: esto es la guerra, describe la dificultad de alcanzar y de que lo mejor que puede hacer una periodista es trabajar con honestidad.

El libro finaliza con un epílogo muy personal donde la autora. "Es innegable que todas las periodistas y, todavía más las veteranas, han hecho y, lamentablemente siguen haciendo, un esfuerzo muy superior al de los hombres para demostrar su valía”. Y también merece la pena destacar la afirmación sobre la asunción de roles: "Aún se cuestiona el hecho de que una corresponsal de guerra sea madre, que desee ser enviada a zonas peligrosas o que la contraten para desempeñar este tipo de trabajo, cuando en el caso de los hombres no se concibe está mal entendida incompatibilidad". A pesar de los numerosos estudios en torno a la igualdad, ésta sigue sin lograrse en el siglo XXI. Todavía en los contextos donde predomina la presencia masculina, la femenina se siente en minoría para poder defenderse. Se asumen roles que le son propios y prácticamente indiscutibles. Igual que en el periodismo, el cine sigue teniendo minoría femenina representada en los cargos directivos. Se trata de una profesión, que, como otras, está ligada más al sector masculino, y tanto 
es así que, incluso, en algo tan poco significativo como podría pensarse que es la composición de los jurados de un festival de cine, siguen estando más representados por hombres que por mujeres. Un aspecto que de alcanzarse garantizaría diversidad y calidad en la decisión unánime representada con enfoques diversos de los miembros que lo componen (Jurado, 2018: 185).

\section{Bibliografía:}

Del Paso, A. (Coords.) (2018). Reporteras españolas, testigos de guerra. De las pioneras a las actuales. Barcelona: Penguin Random House Grupo Colección: Debate. ISBN: 978-84-9992-830-2, 334 págs.

Jurado Martín, M. (2018). "Festivales de cine online en España: pocos, efímeros, pero de calidad". En Muñuz, Martínez, Peña (Coords.) La realidad audiovisual como nuevo vehículo de comunicación. Barcelona: Gedisa. Pp. 175-191. 
MHCJ Vol. 11 (2) | Año 2020- Reseña nº 2 (11) - Páginas 345 a 350 - mhjournal.org

\section{(c) (†) ()}

Licencia Creative Commons

Miguel Hernández Communication Journal mhjournal.org

\section{Cómo citar este texto:}

Montserrat Jurado Martín (2020): Las mujeres periodistas en primera línea: reporteras en la cobertura de conflictos, Miguel Hernández Communication Journal, Vol. 11 (2), pp. 345 a 350. Universidad Miguel Hernández, UMH (Elche-Alicante). DOI: http://dx.doi.org/10.21134/mhcj.v11i0.348 